\title{
Life History Theory: Evolutionary mechanisms and gender role on risk-taking behaviors in young adults
}

\author{
Javier Salas-Rodríguez *, Luis Gómez-Jacinto, María Isabel Hombrados-Mendieta \\ Department of Social Psychology, Social Work, Social Anthropology and Studies of Eastern Asia, Faculty of Social and Labor Studies, Málaga University, Málaga, Spain
}

\section{A R T I C L E I N F O}

\section{Keywords:}

Life History Theory

Risk-taking behavior

Evolutionary domain-specific risk

Gender differences

Young adults

\begin{abstract}
A B S T R A C T
Evolutionary psychology considers the human mind to be composed of multiple specific mechanisms with specific adaptive purposes. This evolutionary approach is in line with the domain-specific view of risk-taking behaviors. Based on the theoretical framework of Life History Theory, the present study analyzes the moderating effect of gender and the mediating effect of evolutionary domain-specific risks in young adult Spaniards (432 participants). $K$-factor, measured through the Mini-K, was used as an indicator of life history strategy (LHS). Evolutionary domain-specific risks were measured through the Evolutionary Domain-Specific Risk Scale and risktaking behaviors through the Risky Behavior Questionnaire. Results showed an interaction effect between gender and LHS for rule breaking. Evolutionary domain-specific risks had a mediation effect between LHS and risktaking behaviors, mainly through mate attraction. These results highlight the different effects of LHS on risktaking behaviors based on gender and the impact of evolutionary mechanisms. It is, therefore, necessary to consider an evolutionary approach on intervention programs aimed at reducing risk-taking behaviors in young adults.
\end{abstract}

\section{Introduction}

Young adulthood is the developmental period of the life cycle with the highest incidence of risk-taking behaviors (Duell et al., 2018). These behaviors are related to the main external causes of death among young adult Spaniards, such as traffic accidents, suicide and self-inflicted injuries, drowning, homicide, accidental falls or poisoning due to psychotropic drugs; with an overrepresentation of males (Instituto Nacional de Estadística, 2019). This makes it essential to determine which mechanisms are involved in risk-taking behaviors and design effective interventions that would reduce the incidence of such risks.

The present study has been carried out within the theoretical framework of evolutionary psychology. In broad terms, evolutionary psychology proposes that the human mind is composed of multiple evolved mechanisms with specific purposes to solve specific adaptative and recurring problems (e.g. food acquisition, mating, parenting, social exchanges, avoiding contamination from pathogens, etcetera) (Cosmides \& Tooby, 1994). This domain-specific approach on human behavior is in line with the domain-specific approach of risk-taking behaviors (Nicholson et al., 2005; Weber et al., 2002; Wilke et al., 2014). In this context, Wilke et al. (2014) developed the Evolutionary
Domain-Specific Risk Scale (ERS). The ERS was created based on a set of modern actions that are qualitatively similar to recurring domainspecific problems in our ancestral environment (Fig. 1). In short, these domain-specific risks are not only related to negative results, but also positive evolutionary advantages such as food acquisition, gaining status or attracting a potential mate, among other.

The development of the ERS is framed within the Life History Theory (LHT), a middle-level theory that explains how organisms allocate resources and energy for two biologically essential purposes: survival and reproduction (Stearns, 1992). Differences in individuals' allocation of resources and energy to the different domains of survival and reproduction generate differences in their life history strategies (LHS). These strategies can be categorized as tradeoffs, where survival and growth (somatic effort), and reproduction (reproductive effort) would be at the opposite ends of a single dimension. Likewise, reproductive effort can be divided in one dimension where reproductive effort (allocating resources for the attraction and retention of a mate) would be at one end and parenting effort (allocating resources to improve the survival of descendants) would be at the other end (Shennan, 2002).

Differential-K Theory has been proposed to explain individual differences in humans' LHS, being $K$-factor an index used to measure such

\footnotetext{
* Corresponding author.

E-mail addresses: jsalas@uma.es (J. Salas-Rodríguez), jacinto@uma.es (L. Gómez-Jacinto), mihombrados@uma.es (M.I. Hombrados-Mendieta).
} 
differences (Figueredo et al., 2005; Rushton, 1985). In short, an individual can be classified as a fast LHS (low- $K$ ), characterized by low parental investment, high mating effort, short-term mating, low group altruism, criminality, and high risk-taking; or as a slow LHS (high- $K$ ), which is characterized by high parental investment, long-term mating, high group altruism, law abidingness, and low risk-taking (Figueredo et al., 2005, 2006). It is important to consider that from a LHT approach neither strategy is maladaptive, on the contrary, it depends on the context where it is expressed: in unsafe environments with higher risks of death or disability, fasts strategists would have higher adaptive advantage, since their development is faster and the number of descendants higher; in a more predictable environment with less risks for survival, slow strategists will be more prepared to compete with other individuals, given their higher allocation of resources and energy to their own development and that of their descendants (Ellis et al., 2009).

As mentioned before, LHS's adaptive logic has been applied to risktaking behaviors. More specifically and from an evolutionary standpoint, risk-taking behaviors are not interpreted as dysfunctional behaviors, but as part of a fast LHS (Figueredo et al., 2005) . Aggression (Figueredo \& Jacobs, 2010), unsafe sexual practices (Figueredo et al., 2006), drug abuse (Brumbach et al., 2009) or deception (Reynolds \& McCrea, 2015) are examples of risk-taking behaviors which provide adaptive advantages. In addition, males tend to show fast LHS compared to females (Figueredo et al., 2011, 2013; Gladden et al., 2008, 2013; Jonason et al., 2013; Kiire, 2020). Due to their greater variation in reproductive success, males tend to be immersed in reproductive competition, mainly in the form of inter-male competition (Archer, 2009; Betzig, 2012; Ellis et al., 2012) . Moreover, higher female parental investment makes the mating choice mostly a female issue (Trivers, 1972), which intensifies inter-male competition. In contrast, females show greater avoidance of risk-taking behaviors due to their essential role in the survival of their offspring (Campbell, 1999). As a result, males are higher risk-takers in comparison to females in a wide range of domains (Archer, 2019; Byrnes et al., 1999). The extreme consequence is a greater number of male deaths from external causes, which peaks in young adulthood (Kruger \& Nesse, 2006).

Although males in general are more involved in risk-taking than females, a risk-taking strategy could be disadvantageous for a slow LHS male, given his greater investment in parental effort. In fact, compared to other male mammals, human males provide direct parental investment to their offspring (Geary, 2000), a feature that relates to a slow LHS. However, males in monogamous species like humans could maintain some traits associated with promiscuous mating (Trivers, 1972). The implication is that, in human species, some males can express a parental strategy, whereas other males express a mating strategy, something that is known as alternative reproductive strategies (Gross, 1996). One prediction derived from this implication is that males with high parental investment would express attributes similar to females; whereas males with low parental investment would show attributes different from females and high investing males (Archer \& Mehdikhani, 2003). This prediction has been observed in a wide range of attributes, with greater male than female variance in intelligence, physical aggression, mate choice, personality, cooperation, and physical parameters (Archer and Mehdikhani, 2003; Borkenau et al., 2013; Hedges \& Nowell, 1995; Lehre et al., 2009; Thöni et al., 2020). By contrast, a metaanalysis did not find greater male than female variance in psychological attributes related to risk-taking (Cross et al., 2011).

One of the predictors used for the study of risk-taking behaviors is risk propensity, understood as an attitude towards taking or avoiding risks (Rohrmann, 2005). Risk propensity is a good predictor of risky behaviors such as alcohol and substance use (MacPherson et al., 2010; Williams et al., 2010), risky sexual behaviors (Lejuez et al., 2004), or risky driving (Hatfield \& Fernandes, 2009). Furthermore, risk propensity has shown mediating effects between personality traits and unsafe behavioral intention and risk perception (Wang et al., 2016; Zhang et al., 2020), and between sex and aggression (Campbell and Muncer, 2009). Risk propensity is considered a personal trait that can change throughout time, in contrast to a stable dispositional trait pattern (Sitkin \& Weingart, 1995). In fact, a trend of decline across the life span of risk propensity in different countries has been found (Mata et al., 2016). As a result, young adulthood tends to be the stage of the life cycle where there is more propensity towards risk-taking, in line with the higher involvement in risk-taking behaviors observed in this age group.

\subsection{Present study}

Research has demonstrated that males are more likely than females to engage in risk-taking behaviors, that risk-taking behaviors are part of fast LHS, and that males express fast LHS to a greater extent than females. But, do females with fast LHS take more risks? Is there an overlap where males engaging in slow LHS are more cautious than females engaging in fast LHS? And finally, what are the evolutionary mechanisms through which LHS influences risk-taking behaviors? With the aim of answering these questions, the present study has the following main objectives: 1) to check the moderating effect of gender on the direct association between LHS and risk-taking behaviors; 2) to analyze the mediating effect of evolutionary domain-specific risks between LHS and risk-taking behaviors. We expect to find gender differences in the direct effect of LHS, measured through $K$-factor, on risk-taking behaviors; and that LHS will have an indirect effect on risk-taking behaviors through evolutionary domain-specific risks (Fig. 2). Results could underline the need to take into consideration gender and young adults' motivations in intervention programs aimed at reducing risk-taking behaviors, in line with an evolutionary approach. In this sense, instead

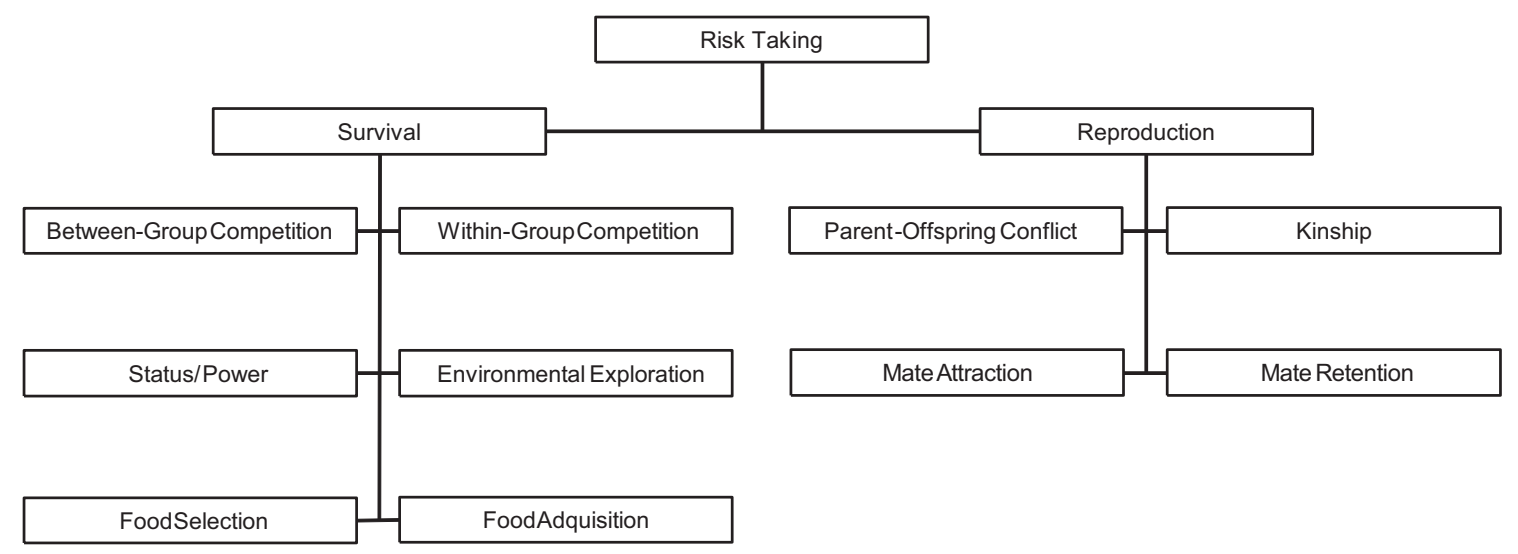

Fig. 1. Conceptual organization of evolutionary risk domains.

(Extracted from Wilke et al., 2014.) 


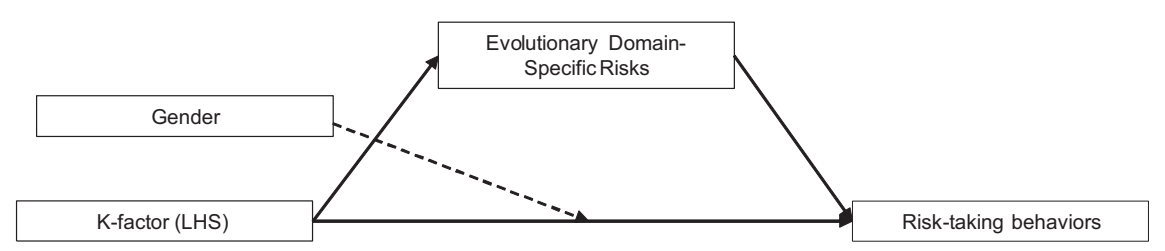

Fig. 2. Theoretical model of the conditional direct and the indirect effect of LHS on risk-taking behaviors.

of considering risk-taking as illogical, such intervention programs could benefit from recognizing the fitness value of risk-taking, mainly in males (Ellis et al., 2012; Nell, 2002), but also in females (Saad \& Peng, 2006). Therefore, analyzing which evolutionary-domains are implicated in each domain of risk-taking behaviors could be the first step in designing more precise and effective intervention programs.

\section{Method}

\subsection{Participants and procedure}

Students of Social Psychology were trained to hand in the instruments with face-to-face survey methodology in exchange of a bonus in the subject. In total, there were 432 participants ( 223 females; mean age $\mathrm{M}=23,57 ; \mathrm{SD}=3,57$ ). Participants gave verbal consent and were asked their telephone number and/or e-mail address to subsequently confirm they had completed the questionnaire. Ethical approval for this study was granted by the Ethical Committee on Experimentation from the University of Malaga (CEUMA) (Registry number: 45-2018-H).

\subsection{Measures}

\subsubsection{Mini-K}

The Spanish version of the Mini-K questionnaire was applied (Figueredo et al., 2006, 2014; Figueredo \& Gaxiola, 2007). The Mini-K is a brief self-reporting instrument composed of 20 items that measure individual differences in a single multivariate latent construct, the $K$-factor. High- $K$ individuals are characterized by a slow LHS, while low- $K$ individuals tend to show fast LHS. Answer format is a 7-point scale, ranging from -3 (strongly disagree) to +3 (strongly agree). There was an intermediate option of 0 (Don't know/Not applicable). Participants' global scores range from -60 to +60 . The total score is calculated by adding scores from all items in the questionnaire. Internal consistency analysis of Mini-K through Cronbach's coefficient showed a value of 0.72 .

\subsubsection{Evolutionary domain-specific risk scale (ERS)}

The ERS is composed of 30 items that assess individuals' propensity to take risks in 10 domains of evolutionary content grouped in two broad categories: survival and reproduction (Fig. 1) (Wilke et al., 2014). Each domain is composed of three items, answered through a 7-point scale with values ranging from 1 (extremely unlikely) to 7 (extremely likely). Total scores from each domain were extracted by adding the scores from all items in each domain. Cronbach's values were 0.68 for betweengroup competition, 0.76 for within-group competition, 0.71 for status/ power, 0.73 for environmental exploration, 0.73 for food selection, 0.33 for food acquisition, 0.75 for parent/offspring conflict, 0.74 for kinship, 0.63 for mate attraction, and 0.36 for mate retention.

\subsubsection{Risky Behavior Questionnaire (RBQ)}

$\mathrm{RBQ}$ is a self-reporting questionnaire comprised of 20 items that assess individuals' involvement in a wide range of risk-taking behaviors over the last month (Auerbach \& Gardiner, 2012). With the aim of increasing probabilities for participants to have been involved in risktaking behaviors, this period was extended to three months for the present study. The RBQ assesses individuals' involvement in the following domains of risk-taking behaviors: (a) unsafe sexual practices, (b) aggressive and/or violent behaviors, (c) rule breaking, (d) dangerous, destructive and illegal behaviors, (e) self-injurious behaviors, and (f) substance use. The answer format is a 5-point scale: (0) Never; (1) Almost never (once a month); (2) Sometimes (2-3 times per month); (3) Almost always (2-3 times per week); and (4) Always (4 or more times per week). Participants' global scores range between 0 and 80, where high scores indicate higher levels of risk-taking behaviors. Each participant's score was obtained from adding the scores from all items in the questionnaire. Domains of risk-taking behaviors were obtained by adding scores from the items in each domain. The internal consistency analysis of global RBQ showed a value of $\alpha=0.83$. Regarding the six domains of the RBQ, Cronbach's values were 0.25 for unsafe sexual practices, 0.69 for aggressive and/or violent behaviors, 0.65 for rule breaking, 0.55 for dangerous, destructive and illegal behaviors, 0.26 for self-injurious behaviors, and 0.54 for substance use.

\subsection{Data analysis}

$t$-tests were conducted to check gender differences in LHS, risktaking behaviors and evolutionary domain-specific risks. Pearson's analysis was used to test the associations between the variables included in the present study. Lastly, Model 5 from macro Process (using 5.000 bootstrapping samples) was used to investigate the moderation effect of gender between LHS and risk-taking behaviors, as well as the mediating effect of evolutionary domain-specific risks between LHS and risk-taking behaviors (Hayes, 2013). LHS was considered the independent variable, gender the moderating variable, and evolutionary domain-specific risks were considered the mediating variables in all models. For the first model, global risk-taking behaviors was introduced as dependent variable, while each specific domain of risk-taking behaviors were dependent variable in the remaining models (Fig. 1).

$K$-factor, evolutionary domain-specific risks, risk-taking behaviors and age were standardized for the mediation analysis with moderation effect models. The purpose of the standardization was to improve the interpretation of regression coefficients in the models. Age was introduced as co-variable in each model.

\section{Results}

\subsection{Preliminary analysis}

Table 1 shows a general trend in participants towards slow LHS (high- $K$ ), as well as low involvement in risk-taking behaviors. Results also show that rule breaking and substance use showed the highest scores, and self-injurious behaviors the lowest. Regarding evolutionary domain-specific risks, kinship showed the highest risk propensity, while status/power showed the opposite.

As it can be seen in Table 1, males showed fast LHS (low- $K$ ) and higher involvement in global risk-taking behaviors compared to females. Regarding risk-taking behaviors domains, significant differences were only found in unsafe sexual practices and dangerous, destructive and illegal behaviors, with males showing higher scores in both domains. Regarding evolutionary domain-specific risks, gender differences were found in six of the ten domains. Males showed higher risk propensity in between-group competition, within-group competition, status/power, 
Table 1

Descriptive statistics (total, males and females) and gender differences mean.

\begin{tabular}{|c|c|c|c|c|c|}
\hline & \multirow{2}{*}{$\frac{\text { Total }}{M(S D)}$} & \multirow{2}{*}{$\frac{\text { Females }}{M(S D)}$} & \multirow{2}{*}{$\frac{\text { Males }}{M(S D)}$} & \multicolumn{2}{|l|}{$t$-Test } \\
\hline & & & & $t$ & $d$ \\
\hline $\begin{array}{l}\text { Mini-K } \\
K \text {-factor }\end{array}$ & $\begin{array}{l}27.93 \\
(11.67)\end{array}$ & $\begin{array}{l}29.83 \\
(10.64)\end{array}$ & $\begin{array}{l}25.89 \\
(12.38)\end{array}$ & $-3.55^{* * *}$ & 0.34 \\
\hline $\begin{array}{l}\text { RBQ } \\
\text { Global risk-taking } \\
\text { behaviors }\end{array}$ & $\begin{array}{l}12.10 \\
(8.55)\end{array}$ & $\begin{array}{l}11.00 \\
(7.60)\end{array}$ & $\begin{array}{l}13.26 \\
(9.34)\end{array}$ & $2.75^{* *}$ & 0.27 \\
\hline $\begin{array}{l}\text { RBQ domains } \\
\text { Unsafe sexual practices }\end{array}$ & $\begin{array}{l}1.29 \\
(1.54)\end{array}$ & $\begin{array}{l}1.10 \\
(1.43)\end{array}$ & $\begin{array}{l}1.48 \\
(1.63)\end{array}$ & $2.57^{*}$ & 0.25 \\
\hline $\begin{array}{l}\text { Aggressive and/or } \\
\text { violent behaviors }\end{array}$ & $\begin{array}{l}1.72 \\
(2.20)\end{array}$ & $\begin{array}{l}1.52 \\
(2.10)\end{array}$ & $\begin{array}{l}1.93 \\
(2.31)\end{array}$ & 1.94 & 0.19 \\
\hline Rule breaking & $\begin{array}{l}3.16 \\
(2.30)\end{array}$ & $\begin{array}{l}3.16 \\
(2.12)\end{array}$ & $\begin{array}{l}3.16 \\
(2.48)\end{array}$ & 0.01 & 0.00 \\
\hline $\begin{array}{l}\text { Dangerous, } \\
\text { destructive, and } \\
\text { illegal behaviors }\end{array}$ & $\begin{array}{l}1.92 \\
(2.25)\end{array}$ & $\begin{array}{l}1.35 \\
(1.82)\end{array}$ & $\begin{array}{l}2.53 \\
(2.50)\end{array}$ & $5.54^{* * *}$ & 0.54 \\
\hline $\begin{array}{l}\text { Self-injurious } \\
\text { behaviors }\end{array}$ & $\begin{array}{l}0.56 \\
(0.94)\end{array}$ & $\begin{array}{l}0.61 \\
(1.00)\end{array}$ & $\begin{array}{l}0.51 \\
(0.87)\end{array}$ & -1.13 & 0.11 \\
\hline Substance use & $\begin{array}{l}3.44 \\
(2.85)\end{array}$ & $\begin{array}{l}3.25 \\
(2.66)\end{array}$ & $\begin{array}{l}3.65 \\
(3.04)\end{array}$ & 1.46 & 0.14 \\
\hline \multicolumn{6}{|l|}{ ERS domains } \\
\hline $\begin{array}{l}\text { Between-group } \\
\text { competition }\end{array}$ & $\begin{array}{l}7.83 \\
(4.36)\end{array}$ & $\begin{array}{l}7.24 \\
(3.97)\end{array}$ & $\begin{array}{l}8.46 \\
(4.66)\end{array}$ & $2.93^{* *}$ & 0.28 \\
\hline $\begin{array}{l}\text { Within-group } \\
\text { competition }\end{array}$ & $\begin{array}{l}9.93 \\
(4.39)\end{array}$ & $\begin{array}{l}9.47 \\
(4.42)\end{array}$ & $\begin{array}{l}10.42 \\
(4.33)\end{array}$ & $2.26^{*}$ & 0.22 \\
\hline Status/power & $\begin{array}{l}5.57 \\
(3.32)\end{array}$ & $\begin{array}{l}5.09 \\
(2.76)\end{array}$ & $\begin{array}{l}6.08 \\
(3.76)\end{array}$ & $3.09 * *$ & 0.30 \\
\hline $\begin{array}{l}\text { Environmental } \\
\text { exploration }\end{array}$ & $\begin{array}{l}10.39 \\
(4.92)\end{array}$ & $\begin{array}{l}9.04 \\
(4.68)\end{array}$ & $\begin{array}{l}11.83 \\
(4.77)\end{array}$ & $6.13^{\text {*** }}$ & 0.59 \\
\hline Food selection & $\begin{array}{l}12.66 \\
(4.71)\end{array}$ & $\begin{array}{l}13.01 \\
(4.57)\end{array}$ & $\begin{array}{l}12.27 \\
(4.83)\end{array}$ & -1.64 & 0.16 \\
\hline Food acquisition & $\begin{array}{l}9.22 \\
(3.89)\end{array}$ & $\begin{array}{l}8.82 \\
(3.68)\end{array}$ & $\begin{array}{l}9.65 \\
(4.06)\end{array}$ & $2.21^{*}$ & 0.21 \\
\hline Parent-offspring & $\begin{array}{l}10.66 \\
(5.35)\end{array}$ & $\begin{array}{l}10.74 \\
(5.48)\end{array}$ & $\begin{array}{l}10.57 \\
(5.23)\end{array}$ & -0.33 & 0.03 \\
\hline Kinship & $\begin{array}{l}19.02 \\
(2.91)\end{array}$ & $\begin{array}{l}19.12 \\
(2.83)\end{array}$ & $\begin{array}{l}18.91 \\
(3.00)\end{array}$ & -0.74 & 0.07 \\
\hline Mate attraction & $\begin{array}{l}6.92 \\
(3.93)\end{array}$ & $\begin{array}{l}6.37 \\
(3.65)\end{array}$ & $\begin{array}{l}7.50 \\
(4.13)\end{array}$ & $3.03^{* *}$ & 0.29 \\
\hline Mate retention & $\begin{array}{l}7.26 \\
(3.30)\end{array}$ & $\begin{array}{l}7.18 \\
(3.14)\end{array}$ & $\begin{array}{l}7.34 \\
(3.47)\end{array}$ & 0.49 & 0.05 \\
\hline
\end{tabular}

Males, $n=209$; Females $n=223$.

$$
\begin{gathered}
{ }_{* * *}^{*} \mathrm{p}<.05 . \\
{ }_{* * * *} \mathrm{p}<.01 .
\end{gathered}
$$

environmental exploration, food acquisition and mate attraction.

\subsection{Correlation analysis}

As it was expected, $K$-factor showed a significant negative correlation with global risk-taking behaviors as well as with the six risk-taking behaviors domains (Table 2). Furthermore, evolutionary domains of food selection and kinship correlated positively with $K$-factor. Conversely, food acquisition, mate attraction and mate retention showed negative correlations with $K$-factor.

Global risk-taking behaviors showed significant positive correlations with the six specific domains of risk-taking behaviors in which it is comprised. Global risk-taking behaviors also showed significant positive correlations with seven evolutionary domain-specific risks, and significant negative correlations with food selection and kinship. Table 2 shows the remaining correlations. As it can be seen, age shows significant correlations with some of the variables included in the study, so it was treated as a control variable in the mediation analyses with moderation effect.

\subsection{Mediation analysis with moderation effect}

Gender moderated the relation between $K$-factor and rule breaking, showing a conditional direct effect in males but not in females (Table 6). More specifically, slow LHS males show less rule breaking behaviors compared to fast LHS males, and females in general (Fig. 3). We did not find any significant interaction between $K$-factor and gender in the rest of models. However, there were specific conditional direct effects in males for global risk-taking behaviors (Table 3), unsafe sexual practices (Table 4), and substance use (Table 9), with fast LHS males showing greater risk-taking compared to slow LHS males.

With regard to the indirect effects of $K$-factor on risk-taking behaviors through evolutionary domain-specific risks, mate attraction showed a mediating effect in six of the seven models. For all models, $K$-factor predicted lower propensity to take risks in mate attraction (a-path, $b=$ $-0.23, S E=0.05,95 \% \mathrm{CI}-0.32$ to -0.14 ), while mate attraction predicted higher involvement in global risk-taking behaviors (b-path, $b=$ $0.25, S E=0.05,95 \%$ CI, 0.15 to 0.35 ) (Table 3 ), unsafe sexual practices (b-path, $b=0.19, S E=0.06,95 \%$ CI 0.09 to 0.30 ) (Table 4), rule breaking (b-path, $b=0.13, S E=0.05,95 \%$ CI 0.03 to 0.24 ) (Table 6), dangerous, destructive, and illegal behaviors (b-path, $b=0.17, S E=$ $0.05,95 \%$ CI 0.07 to 0.27 ) (Table 7), self-injurious behaviors (b-path, $b$ $=-13, S E=0.06,95 \%$ CI 0.02 to 0.24 ) (Table 8), and substance use (bpath, $b=0.29, S E=0.05$, 95\%CI 0.18 to 0.39 ) (Table 9).

Regarding the rest of evolutionary domains-specific risks, mate retention, food selection and kinship also showed a mediating effect between $K$-factor and risk-taking behaviors. More specifically, $K$-factor predicted lower risk propensity in mate retention (a-path, $b=-0.22, S E$ $=0.05,95 \% \mathrm{CI}-0.31$. to -0.13 ), while mate retention predicted higher involvement in aggressive and/or violent behaviors (b-path, $b=0.12$, $S E=0.05$, 95\%CI 0.03 to 0.22 ) (Table 5). For food selection and kinship, $K$-factor predicted higher risk propensity in both domains (a-path, $b=$ $0.13, S E=0.05,95 \% \mathrm{CI} 0.04$ to 0.23 , for food selection; a-path, $b=0.26$, $S E=0.05$, 95\%CI 0.16 to 0.35 , for kinship); while food selection predicted lower involvement in rule breaking (b-path, $b=-0.10, S E=$ $0.05,95 \% \mathrm{CI}-0.20$ to -0.01 ) (Table 6 ); conversely, kinship predicted higher involvement in rule breaking (b-path, $b=0.11, S E=0.05$, 95\%CI 0.02 to 0.21 ) (Table 6 ).

\section{Discussion}

The present study analyzed the direct effect of LHS on risk-taking behaviors moderated by gender, and the mediating effect of evolutionary domain-specific risks between LHS and risk-taking behaviors. Results showed a moderating effect of gender over rule breaking, with fast LHS males expressing the highest levels of rule breaking and slow LHS males the lowest. However, there were no differences in rule breaking between slow LHS and fast LHS females. Strikingly, males showed higher variability in rule breaking compared to females, with slow LHS males engaging in less rule breaking in comparison with slow LHS females, and fast LHS males engaging in more rule breaking in comparison with fast LHS females. In addition to rule breaking, there were specific conditional direct effects in males over global risk-taking behaviors, unsafe sexual practices, and substance use, with fast LHS scoring higher than slow LHS.

These male intrasexual differences and the greater male than female variability in risk-taking behaviors could be explained by the role of males in rearing. More specifically, we suggest that, with the aim of increasing their reproductive success through offspring survival, slow LHS males would tend to express a risk-avoiding strategy; while fast LHS males would attain reproductive success through mate attraction, thus implying a risk-taking strategy. These male intrasexual differences are in line with the alternative reproductive strategies proposal (Archer \& Mehdikhani, 2003; Gross, 1996), by which some males are better suited for parental effort and other males for reproductive effort. In short, these results could imply considering risk-taking behaviors as a form of inter- 


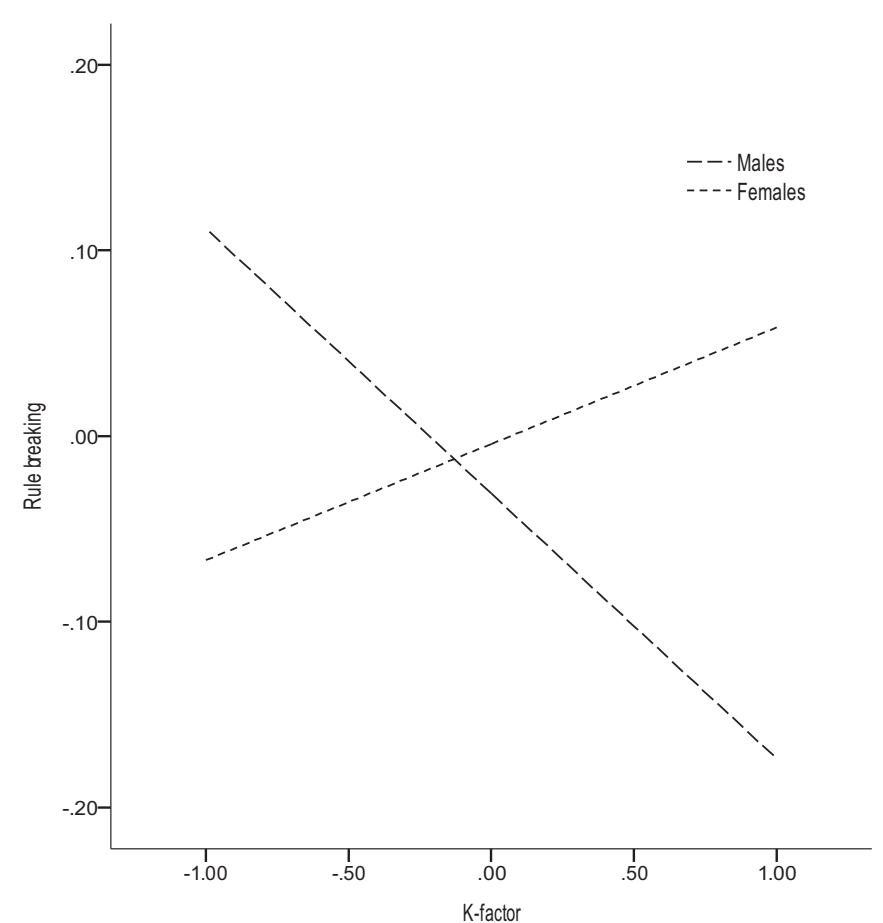

Fig. 3. $K$-factor effect on rule breaking moderated by gender.

Table 3

Standardized specific indirect and conditional direct effects of $K$-factor on general risk-taking behaviors.

\begin{tabular}{lccc}
\hline Variables & Coefficients (SE) & \multicolumn{2}{c}{$95 \%$ bootstrap CI } \\
\cline { 3 - 4 } & & Boot LLCI & Boot ULCI \\
\hline General risk-taking behaviors & & & \\
Indirect effects & & -0.02 & 0.00 \\
Between-group competition & $-0.01(0.03)$ & -0.01 & 0.01 \\
Within-group competition & $-0.00(0.00)$ & -0.03 & 0.01 \\
Status/power & $-0.01(0.01)$ & -0.01 & 0.01 \\
Environmental exploration & $-0.00(0.01)$ & -0.03 & 0.00 \\
Food selection & $-0.01(0.01)$ & -0.01 & 0.03 \\
Food acquisition & $0.01(0.01)$ & -0.01 & 0.01 \\
Parent-offspring & $0.00(0.00)$ & -0.02 & 0.05 \\
Kinship & $0.01(0.02)$ & -0.09 & -0.03 \\
Mate attraction & $-0.06(0.02)$ & -0.03 & 0.01 \\
Mate retention & $-0.01(0.01)$ & & \\
Conditional direct effect & & -0.29 & -0.05 \\
Males & $-0.17(0.06)$ & -0.14 & 0.12 \\
Females & $-0.01(0.07)$ & -0.01 & 0.34 \\
K-factor x gender & $0.17(0.09)$ & \\
Model 1 & $F(14,416)=10.88^{* * * *} ; R^{2}=0.27$ & \\
\hline
\end{tabular}

${ }^{* * * *} p<.001$.

male competition only in fast LHS males. On the other hand, no specific conditional direct effects were found in female LHS over risk-taking behaviors. Moreover, females showed general low levels of risk-taking behaviors, compared to males. These findings imply a risk-avoiding strategy in females, in line with their usual tendency of putting greater effort in parental investment for reproductive success (Campbell, 1999; Trivers, 1972).

The higher male than female variability in risk-taking behaviors is consistent with results obtained in other psychological and physical attributes (Archer and Mehdikhani, 2003; Borkenau et al., 2013; Hedges \& Nowell, 1995; Thöni et al., 2020). Moreover, these results contradict Cross et al. (2011) meta-analysis partially, who did not find greater male variability in risk-taking attributes. In their study, the authors suggested that the exclusion of clinical and incarcerated samples, where males are overrepresented and risk-taking is a factor, could have constrained male 
Table 4

Standardized specific indirect and conditional direct effects of $K$-factor on unsafe sexual practices.

\begin{tabular}{|c|c|c|c|}
\hline \multirow[t]{2}{*}{ Variables } & \multirow[t]{2}{*}{ Coefficients (SE) } & \multicolumn{2}{|c|}{ 95\% bootstrap CI } \\
\hline & & Boot LLCI & Boot ULCI \\
\hline \multicolumn{4}{|l|}{ Unsafe sexual practices } \\
\hline \multicolumn{4}{|l|}{ Indirect effects } \\
\hline Between-group competition & $-0.01(0.01)$ & -0.03 & 0.00 \\
\hline Within-group competition & $-0.00(0.01)$ & -0.02 & 0.01 \\
\hline Status/power & $-0.00(0.00)$ & -0.01 & 0.01 \\
\hline Environmental exploration & $0.00(0.01)$ & -0.01 & 0.02 \\
\hline Food selection & $-0.00(0.01)$ & -0.02 & 0.01 \\
\hline Food acquisition & $0.02(0.01)$ & -0.00 & 0.04 \\
\hline Parent-offspring & $0.00(0.00)$ & -0.01 & 0.01 \\
\hline Kinship & $0.01(0.02)$ & -0.03 & 0.04 \\
\hline Mate attraction & $-0.04(0.01)$ & -0.08 & -0.02 \\
\hline Mate retention & $0.01(0.01)$ & -0.01 & 0.04 \\
\hline \multicolumn{4}{|l|}{ Conditional direct effect } \\
\hline Males & $-0.15(0.07)$ & -0.28 & -0.02 \\
\hline Females & $-0.04(0.07)$ & -0.18 & 0.10 \\
\hline K-factor $\mathrm{x}$ gender & $0.11(0.10)$ & -0.08 & 0.30 \\
\hline Model 2 & \multicolumn{3}{|c|}{$\mathrm{F}(14,416)=4.00^{* * *} ; \mathrm{R}^{2}=0.12$} \\
\hline
\end{tabular}

Table 5

Standardized specific indirect and conditional direct effects of $K$-factor on aggressive and/or violent behaviors.

\begin{tabular}{lccc}
\hline Variables & Coefficients (SE) & \multicolumn{2}{c}{$95 \%$ bootstrap CI } \\
\cline { 3 - 4 } & & Boot LLCI & Boot ULCI \\
\hline Aggressive and/or violent behaviors & & & \\
Indirect effects & & & \\
Between-group competition & $-0.02(0.01)$ & -0.04 & 0.00 \\
Within-group competition & $-0.00(0.00)$ & -0.01 & 0.01 \\
Status/power & $-0.01(0.01)$ & -0.04 & 0.01 \\
Environmental exploration & $0.00(0.01)$ & -0.01 & 0.02 \\
Food selection & $-0.01(0.01)$ & -0.02 & 0.01 \\
Food acquisition & $0.01(0.01)$ & -0.00 & 0.04 \\
Parent-offspring & $0.00(0.00)$ & -0.01 & 0.01 \\
Kinship & $-0.00(0.02)$ & -0.05 & 0.03 \\
Mate attraction & $-0.02(0.01)$ & -0.05 & 0.01 \\
Mate retention & $-0.03(0.01)$ & -0.05 & -0.00 \\
Conditional direct effect & & & \\
Males & $-0.11(0.06)$ & -0.24 & 0.01 \\
Females & $0.00(0.07)$ & -0.13 & 0.13 \\
K-factor x gender & $0.11(0.09)$ & -0.06 & 0.23 \\
Model 3 & $\mathrm{F}(14,416)=1.60 * * * ;$ & $\mathrm{R}^{2}=0.23$ \\
\hline
\end{tabular}

${ }^{* * * *} p<.001$.

Table 6

Standardized specific indirect and conditional direct effects of $K$-factor on rule breaking.

\begin{tabular}{lccc}
\hline Variables & Coefficients (SE) & \multicolumn{2}{c}{$95 \%$ bootstrap CI } \\
\cline { 3 - 4 } & & Boot LLCI & Boot ULCI \\
\hline Rule breaking & & & \\
Indirect effects & & -0.01 & 0.01 \\
Between-group competition & $-0.00(0.01)$ & -0.02 & 0.01 \\
Within-group competition & $-0.00(0.01)$ & -0.01 & 0.01 \\
Status/power & $-0.00(0.00)$ & -0.01 & 0.01 \\
Environmental exploration & $0.00(0.01)$ & -0.03 & -0.00 \\
Food selection & $-0.01(0.01)$ & -0.02 & 0.02 \\
Food acquisition & $-0.00(0.01)$ & -0.02 & 0.03 \\
Parent-offspring & $0.00(0.01)$ & 0.01 & 0.06 \\
Kinship & $0.03(0.02)$ & -0.10 & -0.00 \\
Mate attraction & $-0.03(0.02)$ & -0.04 & 0.01 \\
Mate retention & $-0.02(0.01)$ & & \\
Conditional direct effect & & -0.27 & -0.02 \\
Males & $-0.14(0.06)$ & -0.07 & 0.20 \\
Females & $0.06(.(07)$ & -0.32 & -0.14 \\
K-factor x gender & $0.21(0.05)$ & & \\
Model 4 & $\mathrm{F}(14,416)=7.63^{* * * *} \mathrm{R}^{2}=0.20$ & \\
\hline$* * *$ \\
$\quad$ & & & \\
\hline .001. & & &
\end{tabular}

Table 7

Standardized specific indirect and conditional direct effects of $K$-factor on dangerous, destructive, and illegal behaviors.

\begin{tabular}{|c|c|c|c|}
\hline \multirow[t]{2}{*}{ Variables } & \multirow{2}{*}{$\begin{array}{l}\text { Coefficients } \\
\text { (SE) }\end{array}$} & \multicolumn{2}{|c|}{$95 \%$ bootstrap CI } \\
\hline & & $\begin{array}{l}\text { Boot } \\
\text { LLCI }\end{array}$ & $\begin{array}{l}\text { Boot } \\
\text { ULCI }\end{array}$ \\
\hline \multicolumn{4}{|c|}{$\begin{array}{l}\text { Dangerous, destructive, and illegal } \\
\text { behaviors }\end{array}$} \\
\hline \multicolumn{4}{|c|}{ Indirect effects } \\
\hline Between-group competition & $-0.01(0.01)$ & -0.02 & 0.00 \\
\hline Within-group competition & $0.00(0.00)$ & -0.01 & 0.01 \\
\hline Status/power & $-0.01(0.01)$ & -0.04 & 0.01 \\
\hline Environmental exploration & $-0.01(0.01)$ & -0.02 & 0.00 \\
\hline Food selection & $-0.01(0.01)$ & -0.02 & 0.01 \\
\hline Food acquisition & $-0.01(0.01)$ & -0.03 & 0.02 \\
\hline Parent-offspring & $0.00(0.03)$ & -0.01 & 0.01 \\
\hline Kinship & $0.01(0.01)$ & -0.01 & 0.04 \\
\hline Mate attraction & $-0.04(0.01)$ & -0.07 & -0.01 \\
\hline Mate retention & $-0.01(0.01)$ & -0.03 & 0.01 \\
\hline \multicolumn{4}{|l|}{ Conditional direct effect } \\
\hline Males & $-0.05(0.06)$ & -0.17 & 0.07 \\
\hline Females & $0.06(0.07)$ & -0.07 & 0.20 \\
\hline K-factor x gender & $0.11(0.09)$ & -0.06 & 0.29 \\
\hline Model 5 & \multicolumn{3}{|c|}{$\mathrm{F}(14,416)=9.60^{* * *} ; \mathrm{R}^{2}=0.24$} \\
\hline
\end{tabular}

Table 8

Standardized specific indirect and conditional direct effects of $K$-factor on selfinjurious behaviors.

\begin{tabular}{|c|c|c|c|}
\hline \multirow[t]{2}{*}{ Variables } & \multirow[t]{2}{*}{ Coefficients (SE) } & \multicolumn{2}{|c|}{$95 \%$ bootstrap CI } \\
\hline & & Boot LLCI & Boot ULCI \\
\hline \multicolumn{4}{|l|}{ Self-injurious behaviors } \\
\hline \multicolumn{4}{|l|}{ Indirect Effects } \\
\hline Between-group competition & $0.01(0.01)$ & -0.02 & 0.03 \\
\hline Within-group competition & $0.00(0.00)$ & -0.01 & 0.01 \\
\hline Status/power & $-0.01(0.01)$ & -0.02 & 0.01 \\
\hline Environmental exploration & $0.00(0.01)$ & -0.01 & 0.01 \\
\hline Food selection & $0.00(0.01)$ & -0.01 & 0.02 \\
\hline Food acquisition & $0.00(0.01)$ & -0.02 & 0.02 \\
\hline Parent-offspring & $0.00(0.00)$ & -0.01 & 0.01 \\
\hline Kinship & $-0.00(0.02)$ & -0.03 & 0.03 \\
\hline Mate attraction & $-0.03(0.02)$ & -0.07 & -0.00 \\
\hline Mate retention & $0.00(0.01)$ & -0.02 & 0.03 \\
\hline \multicolumn{4}{|l|}{ Conditional Direct Effect } \\
\hline Males & $-0.11(0.07)$ & -0.24 & 0.03 \\
\hline Females & $-0.13(0.07)$ & -0.28 & 0.01 \\
\hline K-factor x gender & $-0.03(10)$ & -0.22 & 0.17 \\
\hline Model 6 & \multicolumn{3}{|c|}{$\mathrm{F}(14,416)=2.34 * * ; \mathrm{R}^{2}=0.07$} \\
\hline
\end{tabular}

variability more than female variability. However, our normative sample showed greater male than female variability in some risk-taking behaviors.

We also found indirect effects of LHS over risk-taking behaviors through evolutionary domain-specific risks in young adults. In fact, the effect of LHS over the specific domains of aggressive and/or violent behaviors, rule breaking and dangerous, destructive and illegal behaviors was exclusively indirect through evolutionary domain-specific risks, mainly mate attraction. More specifically, results have shown that fast LHS is related to higher risk propensity in mate attraction, which in turn increases global risk-taking behaviors, unsafe sexual practices, rule breaking, dangerous, destructive and illegal behaviors, self-injurious behaviors and substance use. Thus, these results not only suggest the relevance of mate attraction on fast LHS (Ellis et al., 2009), but the functional value of risk-taking behaviors in fast LHS as a mean for attracting potential partners, as it has been seen previously (e.g., Neel et al., 2016; Wilke et al., 2006).

Mate retention has also showed a mediating effect, specifically between $K$-factor and aggressive and/or violent behaviors. Fast strategists 
Table 9

Standardized specific indirect and conditional direct effects of $K$-factor on substance use.

\begin{tabular}{lccc}
\hline Variables & Coefficients (SE) & \multicolumn{2}{c}{$95 \%$ bootstrap CI } \\
\cline { 3 - 4 } & & Boot LLCI & Boot ULCI \\
\hline Substance use & & & \\
Indirect Effects & & & \\
Between-group competition & $-0.00(0.01)$ & -0.02 & 0.01 \\
Within-group competition & $0.00(0.00)$ & -0.01 & 0.01 \\
Status/power & $-0.00(0.01)$ & -0.02 & 0.00 \\
Environmental exploration & $0.00(0.01)$ & -0.01 & 0.01 \\
Food selection & $-0.01(0.01)$ & -0.03 & 0.00 \\
Food acquisition & $0.00(0.01)$ & -0.02 & 0.03 \\
Parent-offspring & $0.00(0.01)$ & -0.01 & 0.01 \\
Kinship & $0.01(0.01)$ & -0.02 & -0.04 \\
Mate attraction & $-0.07(0.02)$ & -0.11 & -0.03 \\
Mate retention & $0.01(0.01)$ & -0.02 & 0.03 \\
Conditional Direct Effect & & & \\
Males & $-0.16(0.07)$ & -0.29 & -0.04 \\
Females & $-0.06(0.07)$ & -0.20 & 0.08 \\
K-factor x gender & $0.10(0.09)$ & -0.08 & 0.29 \\
Model 7 & $\mathrm{F}(14,416)=5.61 * * * \mathrm{R}^{2}=0.16$ & \\
\hline$* * * *$
\end{tabular}

**** $p<.001$.

showed higher risk propensity towards mate retention, in line with their higher reproductive effort (Ellis et al., 2009). At the same time, risk propensity in mate retention predicted higher involvement in aggressive and/or violent behaviors. This finding suggest that fast strategists would tend to show aggressive and/or violent behaviors with the purpose of retaining a sexual partner, thus increasing the risk of intimate partner violence, as have been seen previously (Buss \& Duntley, 2011; Kaighobadi et al., 2009; Kiire, 2019).

Food selection also showed a mediating effect between $K$-factor and rule breaking. Slow strategists showed higher risk propensity in food selection, which in turn predicted lower involvement in rule breaking. It might be striking to find that slow strategists related to risk propensity, specifically in food selection. However, considering that slow LHS relate to higher life expectancy (Ellis et al., 2009; Wilson \& Daly, 1997), it would be beneficial for a slow strategist to take risks with the purpose of selecting healthy and/or quality food, compared to fast strategists, who have lower life expectancy. Moreover, we suggest that the effect of LHS on rule breaking through food selection may be explained in part by conscientiousness, a personality trait characterized by impulse control, conformity, persistence, responsibility, and greater longevity (Nettle, 2006), and that is positively associated with slow LHS (Chen et al., 2017; Gladden et al., 2009). Conscientiousness also predicted positively healthy behaviors like fruit consumption (de Bruijn et al., 2009). Therefore, we propose that conscientiousness could explain the relation between LHS, food selection and rule breaking.

Finally, kinship also mediated the effect between LHS and rule breaking. As it was expected, slow LHS related to high risk propensity in kinship, as it has been previously seen (Stewart-Williams, 2007, 2008); by contrast, and quite surprisingly, kinship predicted positively rule breaking. If we look at Fig. 3, we can see that slow LHS females showed higher levels of rule breaking compared to slow LHS males, contrary to LHT predictions. Both slow LHS and females are related to greater investment in kinship compared to fast LHS and males (Figueredo et al., 2005, 2006; Hames \& Draper, 2004; Neyer \& Lang, 2003). We therefore suggest that slow LHS females' involvement in rule breaking through kinship could be partially due to being a mean of obtaining benefits for their relatives, given their survival and reproductive success depend mainly on kin care.

\subsection{Limitations and further research}

One of the main limitations of the present study is related to the low internal consistency of the evolutionary domains of food acquisition and mate retention. In fact, with the purpose of making the Spanish version of the ERS scale more understandable, one item in the domain of food acquisition and one item in the domain of mate retention were translated with a slightly different meaning. When these items were removed from their respective domains, internal consistency increased to $\alpha=$ 0.58 for mate retention and $\alpha=0.40$ for food acquisition. However, both items were maintained because each domain would have otherwise been comprised of two items only.

Another limitation of the study was related to the use of face-to-face survey methodology, where interviewers are present while participants answer the questionnaires. This might affect answers from participants, especially in surveys that include sensitive questions (Tourangeau \& Yan, 2007). In the present study, sensitive questions are found in the three instruments used. As a result, participants are more likely to give socially accepted answers instead of honest ones, despite being informed that confidentiality and anonymity were ensured.

We found higher male than female variability in risk-taking behaviors, in contrast with previous meta-analysis (Cross et al., 2011). However, that research analyzed risk-taking attributes. Therefore, our results are encouraging and should be explored in other samples so as to elucidate potential gender difference in risk-taking variability. Although we suggested possible explanations for the unexpected relations between food selection and kinship and rule breaking, it would be interesting to analyze the mechanisms proposed. More specifically, future research should analyze the role of conscientiousness over food selection and rule breaking, as well as the potential benefits from slow LHS females in kinship through rule breaking behaviors. Future work should also analyze the mediating effects of perceived risks and benefits in the evolutionary domain-specific risks between LHS and risk propensity in these evolutionary domains. It has been previously found that high perception of costs in evolutionary domain-specific risks relates negatively with involvement in such risks, while the correlation is positive the higher the benefit perceived is (Wilke et al., 2014). Therefore, once the effect of LHS over risk propensity in the evolutionary domains is supported, it would be of interest to analyze whether such effect is mediated by the perceived costs and benefits in each of these domains.

\subsection{Implications and conclusion}

Notwithstanding its limitations, the present study shows gender differences in the direct effect of LHS over risk-taking behaviors, as well as indirect effects of LHS through evolutionary mechanisms; specifically, through mate attraction, mate retention, food selection, and kinship. As a result, this study stresses the need to consider both gender and evolutionary mechanisms in the design of intervention programs addressed to reduce risk-taking behaviors in young adults. More specifically, given their higher involvement in risk-taking behaviors, fast LHS males should be the main target of such intervention programs (Ellis et al., 2012; Nell, 2002). Finally, the adaptive function of risk-taking behaviors in young adults highlights the need of working with young adults' objectives, rather than against them, as previously suggested (Ellis et al., 2012). Behavioral alternatives to risk-taking behaviors ought to be suggested to young adults, so they can achieve their objectives, mainly those related to the mate attraction domain.

\section{CRediT authorship contribution statement}

Javier Salas-Rodríguez: Methodology, Formal analysis, Investigation, Data curation, Writing - original draft, Visualization. Luis GómezJacinto: Conceptualization, Writing - review \& editing, Visualization, Project administration. María Isabel Hombrados-Mendieta: Funding acquisition, Validation, Resources.

Declaration of competing interest

None. 


\section{Acknowledgements}

This research was supported by the Andalucía ERDF 2014-20 OP [UMA18-FEDERJA-071] and the Research Grants of the Reina Sofia Centre on Adolescence and Youth.

\section{References}

Archer, J. (2009). Does sexual selection explain human sex differences in aggression? Behavioral and Brain Sciences, 32(3-4), 249-311. https://doi.org/10.1017/ S0140525X09990951.

Archer, J. (2019). The reality and evolutionary significance of human psychological sex differences. Biological Reviews, 94(4), 1381-1415. https://doi.org/10.1111/ brv. 12507 .

Archer, J., \& Mehdikhani, M. (2003). Variability among males in sexually selected attributes. Review of General Psychology, 7(3), 219-236. https://doi.org/10.1037/ 1089-2680.7.3.219.

Auerbach, R. P., \& Gardiner, C. K. (2012). Moving beyond the trait conceptualization of self-esteem: The prospective effect of impulsiveness, coping, and risky behavior engagement. Behaviour Research and Therapy, 50(10), 596-603. https://doi.org/ 10.1016/j.brat.2012.06.002.

Betzig, L. (2012). Means, variances, and ranges in reproductive success: Comparative evidence. Evolution and Human Behavior, 33(4), 309-317. https://doi.org/10.1016/j. evolhumbehav.2011.10.008.

Borkenau, P., McCrae, R. R., \& Terracciano, A. (2013). Do men vary more than women in personality? A study in 51 cultures. Journal of Research in Personality, 47(2), 135-144. https://doi.org/10.1016/j.jrp.2012.12.001.

Brumbach, B. H., Figueredo, A. J., \& Ellis, B. J. (2009). Effects of harsh and unpredictable environments in adolescence on development of life history strategies: A longitudinal test of an evolutionary model. Human Nature, 20(1), 25-51. https://doi. org/10.1007/s12110-009-9059-3.

Buss, D. M., \& Duntley, J. D. (2011). The evolution of intimate partner violence. Aggression and Violent Behavior, 16(5), 411-419. https://doi.org/10.1016/j. avb.2011.04.015.

Byrnes, J. P., Miller, D. C., \& Schafer, W. D. (1999). Gender differences in risk taking: A meta-analysis. Psychological Bulletin, 125(3), 367-383. https://doi.org/10.1037/ 0033-2909.125.3.367.

Campbell, A. (1999). Staying alive: Evolution, culture, and women's intrasexual aggression. Behavioral and Brain Sciences, 22(2), 203-252. https://doi.org/10.1017/ S0140525X99001818.

Campbell, A., \& Muncer, S. (2009). Can "risky" impulsivity explain sex differences in aggression? Personality and Individual Differences, 47(5), 402-406. https://doi.org/ 10.1016/j.paid.2009.04.006.

Chen, B. B., Shi, Z., \& Sun, S. (2017). Life history strategy as a mediator between childhood environmental unpredictability and adulthood personality. Personality and Individual Differences, 111, 215-219. https://doi.org/10.1016/j.paid.2017.02.032.

Cosmides, L., \& Tooby, J. (1994). Origins of domain specificity: The evolution of functional organization. In L. A. Hirschfeld \& S. A. E. Gelman (Eds.), Mapping the mind: Domain specificity in cognition and culture (pp. 85-116). Cambridge University Press. doi: https://doi.org/10.1017/СВО9780511752902.005.

Cross, C. P., Copping, L. T., \& Campbell, A. (2011). Sex differences in impulsivity: A meta-analysis. Psychological Bulletin, 137(1), 97-130. https://doi.org/10.1037/ a0021591.

de Bruijn, G. J., Brug, J., \& Van Lenthe, F. J. (2009). Neuroticism, conscientiousness and fruit consumption: Exploring mediator and moderator effects in the theory of planned behaviour. Psychology \& Health, 24(9), 1051-1069. https://doi.org/ $10.1080 / 08870440802428241$.

Duell, N., Steinberg, L., Icenogle, G., Chein, J., Chaudhary, N., Di Giunta, L., ... Chang, L. (2018). Age patterns in risk taking across the world. Journal of Youth and Adolescence, 47(5), 1052-1072. https://doi.org/10.1007/s10964-017-0752-y.

Ellis, B. J., Del Giudice, M., Dishion, T. J., Figueredo, A. J., Gray, P., Griskevicius, V., ... Wilson, D. S. (2012). The evolutionary basis of risky adolescent behavior: Implications for science, policy, and practice. Developmental Psychology, 48(3), 598-623. https://doi.org/10.1037/a0026220.

Ellis, B. J., Figueredo, A. J., Brumbach, B. H., \& Schlomer, G. L. (2009). Fundamental dimensions of environmental risk: The impact of harsh versus unpredictable environments on the evolution and development of life history strategies. Human Nature, 20(2), 204-268. https://doi.org/10.1007/s12110-009-9063-7.

Figueredo, A. J., Andrzejczak, D. J., Jones, D. N., Smith-Castro, V., \& Montero, E. (2011) Reproductive strategy and ethnic conflict: Slow life history as a protective factor against negative ethnocentrism in two contemporary societies. Journal of Social, Evolutionary, and Cultural Psychology, 5(1), 14-31. https://doi.org/10.1037/ h0099277.

Figueredo, A. J., Cabeza de Baca, T., \& Woodley, M. A. (2013). The measurement of human life history strategy. Personality and Individual Differences, 55(3), 251-255. https://doi.org/10.1016/j.paid.2012.04.033.

Figueredo, A. J., \& Jacobs, W. J. (2010). Aggression, risk-taking, and alternative life history strategies: The behavioral ecology of social deviance. In M. F., \& V. CorralVerdugo (Eds.), Bio-psycho-social perspectives on interpersonal violence (pp. 3-28). Hauppauge, NY: Nova Science Publishers.

Figueredo, A. J., Vásquez, G., Brumbach, B. H., Schneider, S. M. R., Sefcek, J. A., Tal, I. R., ... Jacobs, W. J. (2006). Consilience and Life History Theory: From genes to brain to reproductive strategy. Developmental Review, 26(2), 243-275. https://doi. org/10.1016/j.dr.2006.02.002.
Figueredo, A. J., Vásquez, G., Brumbach, B. H., Sefcek, J. A., Kirsner, B. R., \& Jacobs, W. J. (2005). The K-factor: Individual differences in life history strategy. Personality and Individual Differences, 39(8), 1349-1360. https://doi.org/10.1016/j. paid.2005.06.009.

Figueredo, A. J., Wolf, P. S. A., Olderbak, S. G., Gladden, P. R., Fernandes, H. B. F., Wenner, C., ... Philippe Rushton, J. (2014). The psychometric assessment of human life history strategy: A meta-analytic construct validation. Evolutionary Behavioral Sciences, 8(3), 148-185. https://doi.org/10.1037/h0099837.

Geary, D. C. (2000). Evolution and proximate expression of human paternal investment. Psychological Bulletin, 126(1), 55-77. https://doi.org/10.1037/0033-2909.126.1.55.

Gladden, P. R., Sisco, M., \& Figueredo, A. J. (2008). Sexual coercion and life-history strategy. Evolution and Human Behavior, 29(5), 319-326. https://doi.org/10.1016/j. evolhumbehav.2008.03.003.

Gladden, P. R., Figueredo, A. J., Andrejzak, D. J., Jones, D. N., \& Smith-Castro, V. (2013). Reproductive strategy and sexual conflict slow life history strategy inihibts negative androcentrism. Journal of Methods and Measurement in the Social Sciences, 4(1), 48. https://doi.org/10.2458/v4i1.17774.

Gladden, P. R., Figueredo, A. J., \& Jacobs, W. J. (2009). Life history strategy, psychopathic attitudes, personality, and general intelligence. Personality and Individual Differences, 46(3), 270-275. https://doi.org/10.1016/j.paid.2008.10.010.

Gross, M. R. (1996). Tactics: Diversity within sexes. Trends in Ecology \& Evolution, 2(2), 92-98.

Hames, R., \& Draper, P. (2004). Women's work, child care, and helpers-at-the-nest in a hunter-gatherer society. Human Nature, 15(4), 319-341. https://doi.org/10.1007/ s12110-004-1012-x.

Hatfield, J., \& Fernandes, R. (2009). The role of risk-propensity in the risky driving of younger drivers. Accident Analysis and Prevention, 41(1), 25-35. https://doi.org/ 10.1016/j.aap.2008.08.023.

Hayes, A. F. (2013). Introduction to mediation, moderation, and conditional process analysis: A regression-based approach. New York, NY: Guilford Press.

Hedges, L. V., \& Nowell, A. (1995). Sex differences in mental test scores, variability, and numbers of high-scoring individuals. Science, 269(5220), 41-45. https://doi.org/ 10.1126/science.7604277.

Jonason, P. K., Li, N. P., \& Czarna, A. Z. (2013). Quick and dirty: Some psychosocial costs associated with the dark triad in three countries. Evolutionary Psychology, 11(1), 172-185. https://doi.org/10.1177/147470491301100116.

Kaighobadi, F., Shackelford, T. K., \& Goetz, A. T. (2009). From mate retention to murder: Evolutionary psychological perspectives on men's partner-directed violence. Review of General Psychology, 13(4), 327-334. https://doi.org/10.1037/a0017254.

Kiire, S. (2019). A "fast" life history strategy affects intimate partner violence through the dark triad and mate retention behavior. Personality and Individual Differences, 140 (February 2018), 46-51. https://doi.org/10.1016/j.paid.2018.07.016.

Kiire, S. (2020). Structure of the mini-K-J and its utility for measuring fast life history traits in Japanese undergraduate students. Evolutionary Psychology, 18(1), 1-9. https://doi.org/10.1177/1474704919900633.

Kruger, D. J., \& Nesse, R. M. (2006). An evolutionary life-history framework for understanding sex differences in human mortality rates. Human Nature. https://doi. org/10.1007/s12110-006-1021-z.

Lehre, A. C., Lehre, K. P., Laake, P., \& Danbolt, N. C. (2009). Greater intrasex phenotype variability in males than in females is a fundamental aspect of the gender differences in humans. Developmental Psychobiology, 51(2), 198-206. https://doi.org/10.1002/ dev.20358.

Lejuez, C. W., Simmons, B. L., Aklin, W. M., Daughters, S. B., \& Dvir, S. (2004). Risktaking propensity and risky sexual behavior of individuals in residential substance use treatment. Addictive Behaviors, 29(8), 1643-1647. https://doi.org/10.1016/j. addbeh.2004.02.035.

MacPherson, L., Magidson, J. F., Reynolds, E. K., Kahler, C. W., \& Lejuez, C. W. (2010). Changes in sensation seeking and risk-taking propensity predict increases in alcohol use among early adolescents. Alcoholism: Clinical and Experimental Research, 34(8), 1400-1408. https://doi.org/10.1111/j.1530-0277.2010.01223.x.

Mata, R., Josef, A. K., \& Hertwig, R. (2016). Propensity for risk taking across the life span and around the globe. Psychological Science, 27(2), 231-243. https://doi.org/ $10.1177 / 0956797615617811$.

Neel, R., Kenrick, D. T., White, A. E., \& Neuberg, S. L. (2016). Individual differences in fundamental social motives. Journal of Personality and Social Psychology, 110(6), 887-907. https://doi.org/10.1037/pspp0000068.

Nell, V. (2002). Why young men drive dangerously: Implications for injury prevention. Current Directions in Psychological Science, 11(2), 75-79. https://doi.org/10.1111/ 1467-8721.00172.

Nettle, D. (2006). The evolution of personality variation in humans and other animals. American Psychologist, 61(6), 622-631. https://doi.org/10.1037/0003066X.61.6.622.

Neyer, F. J., \& Lang, F. R. (2003). Blood is thicker than water: Kinship orientation across adulthood. Journal of Personality and Social Psychology, 84(2), 310-321. https://doi. org/10.1037/0022-3514.84.2.310.

Nicholson, N., Soane, E., Fenton-O'Creevy, M., \& Willman, P. (2005). Personality and domain-specific risk taking. Journal of Risk Research, 8(2), 157-176. https://doi.org/ 10.1080/1366987032000123856.

Reynolds, J. J., \& McCrea, S. M. (2015). Exploitative and deceptive resource acquisition strategies: The role of life history strategy and life history contingencies. Evolutionary Psychology, 13(3), 1-21. https://doi.org/10.1177/1474704915593664.

Rushton, J. P. (1985). Differential K theory: The sociobiology of individual and group differences. Personality and Individual Differences, 6(4), 441-452. https://doi.org/ 10.1016/0191-8869(85)90137-0. 
Saad, G., \& Peng, A. (2006). Applying Darwinian principles in designing effective intervention strategies: The case of Sun tanning. Psychology \& Marketing, 23(7), 617-638. https://doi.org/10.1002/mar.20149.

Shennan, S. (2002). Genes, memes and human history: Darwinian archaeology and cultural evolution. NY, London: Thames \& Hudson.

Sitkin, S. B., \& Weingart, L. R. (1995). Determinants of risky decision-making behavior: A test of the mediating role of risk perceptions and propensity. Academy of Management Journal, 38(6), 1573. https://doi.org/10.2307/256844.

Stearns, S. (1992). The evolution of life histories. Oxford: Oxford University Press.

Stewart-Williams, S. (2007). Altruism among kin vs. nonkin: Effects of cost of help and reciprocal exchange. Evolution and Human Behavior, 28(3), 193-198. https://doi. org/10.1016/j.evolhumbehav.2007.01.002.

Stewart-Williams, S. (2008). Human beings as evolved nepotists. Human Nature, 19(4), 414-425. https://doi.org/10.1007/s12110-008-9048-y.

Thöni, C., Volk, S., \& Cortina, J. M. (2020). Greater male variability in cooperation: Meta-analytic evidence for an evolutionary perspective. Psychological Science. https://doi.org/10.1177/0956797620956632.

Tourangeau, R., \& Yan, T. (2007). Sensitive questions in surveys. Psychological Bulletin, 133(5), 859-883. https://doi.org/10.1037/0033-2909.133.5.859.

Trivers, R. L. (1972). Parental investment and sexual selection. In B. Campbell (Ed.), Sexual selection and the descent of man (pp. 136-179). Aldine Publishing Company.

Wang, C. M., Xu, B. B., Zhang, S. J., \& Chen, Y. Q. (2016). Influence of personality and risk propensity on risk perception of Chinese construction project managers. International Journal of Project Management, 34(7), 1294-1304. https://doi.org/ 10.1016/j.ijproman.2016.07.004.

Weber, E. U., Blais, A. R., \& Betz, N. E. (2002). A domain-specific risk-attitude scale: Measuring risk perceptions and risk behaviors. Journal of Behavioral Decision Making 15(4), 263-290. https://doi.org/10.1002/bdm.414.
Wilke, A., Hutchinson, J. M. C., Todd, P. M., \& Kruger, D. J. (2006). Is risk taking used as a cue in mate choice? Evolutionary Psychology, 4, 367-393. https://doi.org/10.1177/ 147470490600400130.

Wilke, A., Sherman, A., Curdt, B., Mondal, S., Fitzgerald, C., \& Kruger, D. J. (2014). An evolutionary domain-specific risk scale. Evolutionary Behavioral Sciences, 8(3), 123-141. https://doi.org/10.1037/ebs0000011.

Williams, L. R., Fox, N. A., Lejuez, C. W., Reynolds, E. K., Henderson, H. A., PerezEdgar, K. E., ... Pine, D. S. (2010). Early temperament, propensity for risk-taking and adolescent substance-related problems: A prospective multi-method investigation. Addictive Behaviors, 35(12), 1148-1151. https://doi.org/10.1016/j. addbeh.2010.07.005.

Wilson, M., \& Daly, M. (1997). Life expectancy, economic inequality, homicide, and reproductive timing in Chicago neighbourhoods. British Medical Journal, 314(7089), 1271-1274.

Zhang, J., Xiang, P., Zhang, R., Chen, D., \& Ren, Y. (2020). Mediating effect of risk propensity between personality traits and unsafe behavioral intention of construction workers. Journal of Construction Engineering and Management, 146(4), 1-12. https://doi.org/10.1061/(ASCE)CO.1943-7862.0001792.

\section{Web references}

Figueredo, A. J., \& Gaxiola, R. J. (2007). The Arizona-Sonora Life History Battery. htt ps://arizona.app.box.com/s/bvzzxw3o7m4312hw3bdmoeqf6n203s18.

Instituto Nacional de Estadística, (INE). (2019). Defunciones según la causa de muerte. https://www.ine.es/jaxiT3/Tabla.htm?t=7947.

Rohrmann, B. (2005). Risk attitude scales: Concepts, questionnaires, utilizations. University of Melbourne, January, 21. http://rohrmannresearch.net/pdfs/rohr mann-racreport.pdf. 